\title{
Qualidade das sementes de pinhão manso submetidas à secagem $\operatorname{artificial}^{1}$
}

\author{
Seed quality of jatropha under different drying air conditions
}

\author{
Renan Ullmann ${ }^{2 *}$, Osvaldo Resende ${ }^{3}$, Juliana de Fátima Sales ${ }^{3}$ e Tarcísio Honório Chaves ${ }^{4}$
}

\begin{abstract}
Resumo - Na fase de pós-colheita do pinhão manso a secagem é o processo mais utilizado para assegurar sua qualidade e estabilidade. Assim, objetivou-se no presente trabalho analisar a secagem das sementes de pinhão manso, bem como verificar o efeito das diversas condições de ar na qualidade do produto, por meio das análises de condutividade elétrica, absorção de água, porcentagem de germinação e índice de velocidade de germinação (IVG). A secagem foi realizada em secador experimental testando as temperaturas de 30;40;50;60 e $70{ }^{\circ} \mathrm{C}$, em delineamento inteiramente casualizado, com quatro repetições. Verificou-se que o aumento da temperatura do ar de secagem aumenta os danos nas sementes de pinhão manso, porém não interfere na absorção de água do produto. Já a germinação se mateve elevada, mesmo na temperatura de secagem mais alta, apresentando valores acima de $91 \%$ e o IVG não apresentou diferenças estatísticas. Portanto, conclui-se que a qualidade fisiológica das sementes de pinhão manso é afetada pela temperatura de secagem.
\end{abstract}

Palavras-chave - Pinhão. Plantas-desidratação. Sementes-qualidade. Germinação.

\begin{abstract}
The post-harvest drying of jatropha is the most frequently used process to ensure quality and stability. The aim of this work was to analyze the seed drying of jatropha and check the effect of air conditions on seed quality, through electrical conductivity, water absorption germination test and index of germination velocity (IGV). Drying was done in an experimental drier, testing controlled temperatures of $30 ; 40 ; 50 ; 60$ and $70{ }^{\circ} \mathrm{C}$, in a randomized design with four replications. It was found that increasing the temperature of the drying air increases the damage on the seeds of jatropha, but does not interfere with water absorption of the product. The germination is high even at the highest drying temperature, with values above $91 \%$ and IVG did not show statistical differences. Therefore, it was concluded that the physiological quality of seeds of Jatropha curcas is affected by drying temperature.
\end{abstract}

Key words - Jatropha. Dehydration-plants. Deed quality. Dermination.

\footnotetext{
*Autor para correspondência

${ }^{1}$ Recebido para publicação em 20/12/2009; aprovado em 12/07/2010

Projeto financiado pelo CNPq

${ }^{2}$ Graduando Do curso de Agronomia do Instituto Federal Goiano, Campus Rio Verde, Rod. Sul Goiana Km 01, Zona Rural, Rio Verde-GO, Brasil, renanullmann@hotmail.com

${ }^{3}$ Diretoria de Ensino de Graduação, Instituto Federal Goiano, Campus Rio Verde, Rio Verde-GO, Brasil, osvresende@yahoo.com.br, julianacefetrv@yahoo.com.br

${ }^{4}$ Graduando do curso de Agronomia do Instituto Federal Goiano, Campus Rio Verde, Rio Verde-GO, Brasil, tarcisiohonoriochaves@ymail.com
} 


\section{Introdução}

Com o incentivo criado pelo Governo Federal brasileiro a partir do Programa de Biodiesel, o plantio de áreas com pinhão manso (Jatropha curcas L.) vem crescendo, tanto por pequenos agricultores como por empresas agrícolas que buscam explorar novos nichos de mercado; isso se deve principalmente às várias vantagens que o pinhão manso apresenta em relação à mamona (oleaginosa indicada pelo governo como primeira escolha para projetos relacionados a agricultura familiar), entre elas: menor exigência hídrica e nutricional, capacidade de recuperação de áreas degradadas em função de suas raízes profundas, além de apresentar maior produtividade média (TEIXEIRA, 2005).

$\mathrm{Na}$ fase de pós-colheita dos produtos vegetais, a secagem é o processo mais utilizado para assegurar sua qualidade e estabilidade considerando que a diminuição da quantidade de água do material reduz a atividade biológica e as mudanças químicas e físicas que ocorrem durante $o$ armazenamento.

Inúmeros trabalhos têm sido realizados com o objetivo de analisar a secagem de sementes de diversas oleaginosas como, por exemplo: pinhão manso (GOLDFARB et al., 2008; PRADHAN et al., 2009; SIRISOMBOON; KITCHAIYA, 2009); canola (CORRÊA et al., 1999); soja (BARROZO et al., 2006; MIRANDA et al., 1999); avelã (OZDEMIR; DEVRES, 1999); girassol (SACILIK et al., 2007); amendoim (CORRÊA et al., 2007) e mamona (GONELI, 2008).

Após o processo de secagem, alguns testes são realizados para avaliar a qualidade das sementes, dentre eles, o teste de germinação, no qual a qualidade fisiológica é avaliada, e os testes para avaliação dos danos mecânicos ocorridos, dentre eles tem-se os testes de condutividade elétrica e de absorção de água.

$\mathrm{O}$ teste de germinação é o principal parâmetro utilizado para a avaliação da qualidade fisiológica das sementes e permite conhecer o potencial de germinação de um lote em condições favoráveis; os resultados do teste são utilizados para determinar a taxa de semeadura, para a comparação do valor de lotes e para a comercialização, pois possibilita a obtenção de resultados comparáveis entre laboratórios (CARVALHO; NAKAGAWA, 2000).

Segundo Araújo et al. (2002), o dano mecânico se refere à injúria causada por agentes físicos no manuseio das sementes, na forma de quebraduras, trincas, cortes e abrasões, podendo ter como conseqüência a redução da sua qualidade fisiológica.

Assim, para avaliação dos danos mecânicos ocorridas nas sementes podem ser utilizadas as análises de condutividade elétrica e de absorção de água. Segundo Vieira (2002), o teste de condutividade elétrica, avalia a qualidade das sementes indiretamente por meio da determinação da quantidade de lixiviados na solução de embebição das sementes.

Por outro lado, a reidratação de materiais é um processo complexo que tem como objetivo reconstituir as características originais das sementes, quando submetido ao contato com uma fase líquida (BILBAOSÁINZ et al., 2005). A absorção de água depende da diferença entre o teor de água de saturação e o teor de água em um determinado tempo, chamada força motriz (RESIO et al., 2005). Assim, a absorção de água é um bom parâmetro para análise da danificação mecânica ocorrida, pelo fato de seus valores estarem ligados aos danos causados no tegumento e na estrutura dos grãos, principalmente em função das elevadas taxas de secagem submetidas as sementes.

$\mathrm{Na}$ literatura, existe carência de informações a respeito das alterações que podem ocorrer nas características das sementes de pinhão manso durante a secagem. Portanto, torna-se relevante a execução de trabalhos referentes ao assunto, podendo assim gerar informações que possibilitem a secagem de forma mais eficiente das sementes com a manutenção da sua qualidade. Assim, objetivou-se verificar o efeito da temperatura de secagem sob a qualidade fisiológica de sementes de pinhão manso.

\section{Material e métodos}

O presente trabalho foi realizado no Laboratório de Pós-colheita de Produtos Vegetais e no Laboratório de Sementes do Instituto Federal de Educação, Ciência e Tecnologia Goiano - Campus Rio Verde (IFGoiano Campus Rio Verde).

A colheita dos frutos e o beneficiamento das sementes foram realizados manualmente. $\mathrm{O}$ teor de água inicial das sementes foi de, aproximadamente, 0,67 (decimal b.s.). Em seguida, as sementes ficaram expostas em ambiente natural para reduzir e homogeneizar o seu teor de água até 0,30 (decimal b.s.).

A secagem das sementes de pinhão manso foi realizada em secador experimental sendo avaliada as temperaturas controladas de $30{ }^{\circ} \mathrm{C} ; 40{ }^{\circ} \mathrm{C} ; 50{ }^{\circ} \mathrm{C} ; 60{ }^{\circ} \mathrm{C}$ e $70{ }^{\circ} \mathrm{C}$ e umidades relativas de $55,98 \% ; 41,44 \% ; 35,35 \%$; $26,21 \%$ e $13,37 \%$, respectivamente. Durante o processo de secagem, as bandejas com as amostras foram pesadas periodicamente até atingirem teores de água de $0,093 \pm 0,011$ (decimal b.s.) definido como o teor de água recomendado para armazenamento seguro das sementes. 
Os teores de água das sementes foram determinados por gravimetria, utilizando-se a estufa a $105 \pm 1^{\circ} \mathrm{C}$, durante 24 horas, em três repetições (BRASIL, 1992).

A temperatura e a umidade relativa do ar de secagem foram monitoradas por meio de um psicrômetro instalado no interior do secador.

O teste de germinação foi conduzido com quatro subamostras de 25 sementes de cada lote, em rolos de papel toalha tipo "Germitest", em germinador tipo "Mangesdorf" regulado para manter a temperatura constante de $25 \pm 1{ }^{\circ} \mathrm{C}$. A quantidade de água adicionada foi equivalente a 2,5 vezes a massa do substrato seco, visando o umedecimento adequado e, consequentemente, a uniformização do teste. Para obter o índice de velocidade de germinação (IVG), conforme metodologia descrita por Maguirre (1962), as interpretações foram efetuadas a partir do $2^{\circ}$ dia depois da semeadura até os 25 dias, verificando as sementes que germinaram, sem a contagem de plântulas normais e a porcentagem média de germinação foi obtida segundo os critérios estabelecidos nas Regras para Análise de Sementes (BRASIL, 2009), avaliando-se as sementes que tiveram emissão de radícula.

O teste de condutividade elétrica foi realizado, segundo metodologia escrita por Vieira e Krzyzanowski (1999). Foram contadas e pesadas quatro subamostras de 20 sementes, de cada tratamento. As amostras foram colocadas em copos de plástico com $75 \mathrm{~mL}$ de água deionizada e mantidas em uma câmara com temperatura controlada a $25 \pm 2{ }^{\circ} \mathrm{C}$, durante 24 horas. Após esse período, foi efetuada a leitura da condutividade elétrica por meio de um condutivímetro de bancada.

A embebição do produto foi realizada em câmara climática com a temperatura regulada em $25 \pm 2{ }^{\circ} \mathrm{C}$. Foi utilizado um becker (capacidade de $100 \mathrm{~mL}$ ) contendo $40 \mathrm{~mL}$ de água destilada juntamente com $10 \mathrm{~g}$ de sementes, perfazendo uma relação em massa de 4:1. Decorrido o período de embebição, as amostras foram retiradas dos beckers e colocadas sobre papel de filtro para escorrimento da água superficial durante dois minutos. O teor de água depois da absorção foi obtido por meio da Equação 1 .

$$
\mathrm{U}^{*}=\frac{\mathrm{M}_{\mathrm{e}}-\mathrm{M}_{\mathrm{s}}}{\mathrm{M}_{\mathrm{s}}}
$$

em que:

$\mathrm{U}^{*}$ : teor de água das sementes, (decimal b.s.);

Me: massa depois da embebição, kg;

Ms: massa da matéria seca do produto, $\mathrm{kg}$.
O experimento foi instalado com cinco tratamentos (temperaturas de secagem de 30;40;50;60 e $70{ }^{\circ} \mathrm{C}$ ), em delineamento inteiramente casualizado, com quatro repetições. Os dados foram analisados por meio de análise de variância pelo teste $\mathrm{F}$, adotando-se o nível de 5\% de probabilidade e para os dados quantitativos foi realizada a análise de regressão.

\section{Resultados e discussão}

Na Figura 1 observam-se as curvas de secagem de sementes de pinhão manso nas diversas condições de temperatura. Verifica-se que o tempo de secagem das sementes de pinhão manso, considerando a redução do teor de água de 0,30 para 0,10 (decimal b.s.) foi de 3,0 horas para a temperatura de $70{ }^{\circ} \mathrm{C}$. Desta forma, observa-se que com o aumento da temperatura ocorreu a diminuição do tempo de secagem, evidenciando a maior velocidade de retirada de água. Este fato também foi observado por Sirisomboon e Kitchaiya (2009) durante a secagem do pinhão manso nas temperaturas de 40;60 e $80^{\circ} \mathrm{C}$; os pesquisadores verificaram ainda que com a elevação da temperatura de secagem aumentou-se a taxa de secagem e diminuiu-se a relação de umidade e o tempo necessário para que o produto chegasse ao teor de água de 0,05 (decimal b.s.).

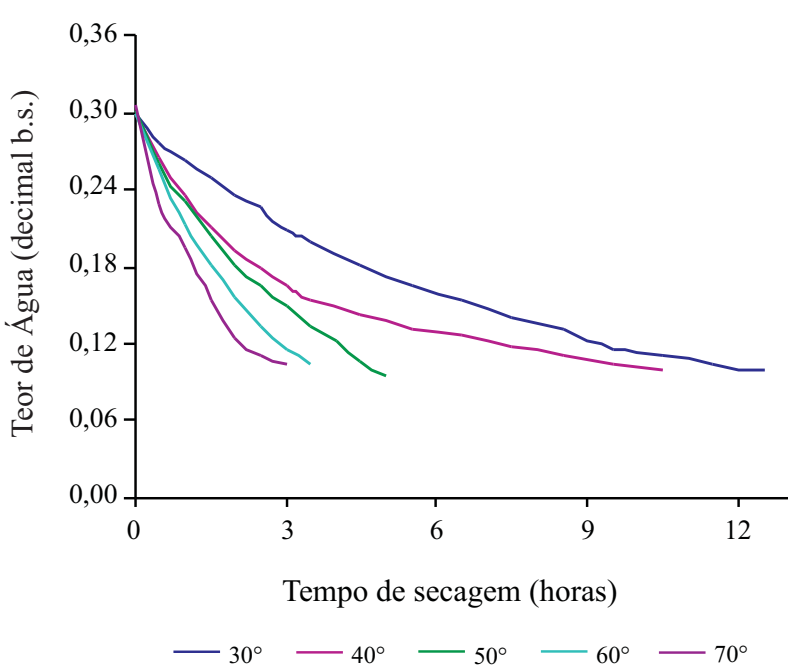

Figura 1 - Curvas de secagem das sementes de pinhão manso sob diferentes temperaturas. Instituto Federal Goiano - IFGoiano - Campos Rio Verde, 2009

Observou-se que o tempo final de secagem foi afetado pela temperatura, notando-se uma diferença maior entre as temperaturas de secagem de $70{ }^{\circ} \mathrm{C}$ e 
$30{ }^{\circ} \mathrm{C}$. Nessas temperaturas as sementes levaram 3,0 e 12,5 horas, respectivamente, para finalizar o processo de secagem. Almeida et al. (2009), durante a secagem do feijão adzuki para as mesmas condições do presente trabalho, evidenciaram que o tempo necessário para o produto atingir o teor de água de 0,11 (decimal b.s.) foi sensivelmente maior que para o pinhão manso, sendo de 49,$0 ; 23,0 ; 16,5 ; 10,0$ e 7,0 horas, para as temperaturas de $30 ; 40 ; 50 ; 60$ e $70{ }^{\circ} \mathrm{C}$, respectivamente. Este fato pode ser explicado, devido ao maior teor de óleo presente nos grãos de pinhão manso, comparativamente ao feijão adzuki, que resulta em uma menor afinidade de água pelo produto e, consequentemente, maior velocidade de secagem.

Na Tabela 1 está apresentado o resumo da análise de variância para as variáveis analisadas.

Tabela 1 - Resumo da análise de variância para a condutividade elétrica, absorção de água, germinação e IVG, durante a secagem das sementes de pinhão manso

\begin{tabular}{ccc}
\hline Variáveis analisadas & $\begin{array}{c}\text { Quadrados } \\
\text { médios }\end{array}$ & $\begin{array}{c}\text { Coeficiente de } \\
\text { variação }(\%)\end{array}$ \\
\hline Absorção de água & $0,0008^{\mathrm{NS}}$ & 3,71 \\
Condutividade elétrica & $0,3543^{* *}$ & 2,86 \\
Germinação & $26,20^{*}$ & 2,93 \\
IVG & $0,6281^{\mathrm{NS}}$ & 8,40 \\
\hline
\end{tabular}

** Significativo a $1 \%$ pelo teste $\mathrm{F}$; *Significativo a $5 \%$ pelo teste $\mathrm{F}$; ${ }^{\text {NS }}$ Não significativo

Observa-se na Tabela 1 que de acordo com o teste $\mathrm{F}$ ao nível de $5 \%$ de probabilidade não foram verificadas diferenças significativas nos valores de absorção de água entre os tratamentos mesmo para as temperaturas de secagem mais elevadas. Este fato pode ser justificado devido ao tegumento do pinhão manso ter se mostrado resistente a entrada de água durante a embebição. A quantidade de água absorvida depende da espécie, semente, variedade ou cultivar, temperatura ambiente, composição química da semente, teor de água inicial, natureza do tegumento e quantidade de água disponível (BEWLEY; BLACK, 1994).

$\mathrm{Na}$ Figura 2, observa-se a condutividade elétrica da solução, em função das temperaturas do ar de secagem. Verificou-se o aumento da condutividade elétrica com a elevação da temperatura de secagem, cujos lixiviados foram mais acentuados nas temperaturas acima de $70{ }^{\circ} \mathrm{C}$. Desta forma, fica evidenciado que temperaturas de secagem acima de $60{ }^{\circ} \mathrm{C}$ removem a água do interior das sementes de pinhão manso com maior agressividade, ocasionando microfissuras em nível celular.
A danificação das sementes em nível celular inicialmente pode provocar alterações fisiológicas e bioquímicas que podem ser identificadas pelo teste de condutividade e não são expressas pela germinação.

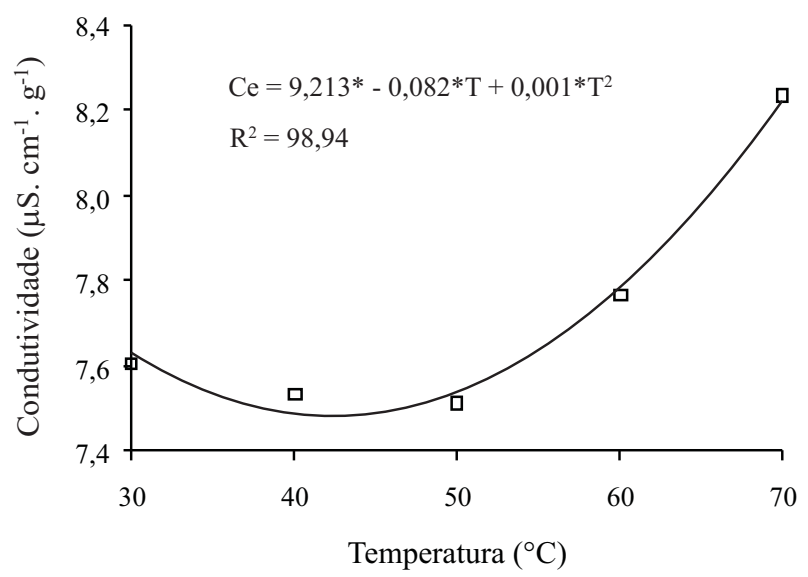

*Significativo a $5 \%$ pelo teste $\mathrm{t}$

Figura 2 - Condutividade elétrica em sementes de pinhão manso sob diferentes temperaturas. Instituto Federal Goiano - IFGoiano - Campos Rio Verde - 2009

Na Figura 3 são apresentados os valores da porcentagem de germinação $G$ durante a secagem de sementes em diferentes de temperatura. Verificou-se que as temperaturas de $30 ; 40 ; 50$ e $60^{\circ} \mathrm{C}$ proporcionaram maiores valores da germinação das sementes de pinhão manso. Em contrapartida, para a temperatura de $70^{\circ} \mathrm{C}$, o valor da germinação foi inferior as demais. Desta forma, esta menor porcentagem de germinação (FIG. 3) para a temperatura de $70{ }^{\circ} \mathrm{C}$ pode ter sido em função de uma deterioração das membranas das células das sementes. Mesmo assim, ainda foi verificada elevada taxa de germinação $(91,25 \%)$, nas sementes submetidas à temperatura de $70^{\circ} \mathrm{C}$. Dependendo das condições ambientais e de secagem, pode haver a redução da qualidade fisiológica das sementes, pela intensificação do fenômeno da deterioração (MARCOS FILHO, 2005).

As temperaturas de $30 ; 40 ; 50$ e $60{ }^{\circ} \mathrm{C}$, não apresentaram diferenças significativas na porcentagem de germinação. Silva et al. (2007) verificaram que a redução do teor de água da soja de $50 \%$ (b.u.) até $20 \%$ (b.u.) não causou prejuízo para a germinação de sementes, durante a secagem com temperatura de até $45^{\circ} \mathrm{C}$.

Verificou-se também uma tendência de menor velocidade de germinação em sementes submetidas à temperatura de secagem de $70{ }^{\circ} \mathrm{C}$, embora não 
tenha sido diferente estatisticamente com relação às demais temperaturas de secagem analisadas conforme apresentado na Tabela 1. Fujii (2007) também verificou que a germinação de sementes de canola foi reduzida com aumento da temperatura de secagem.

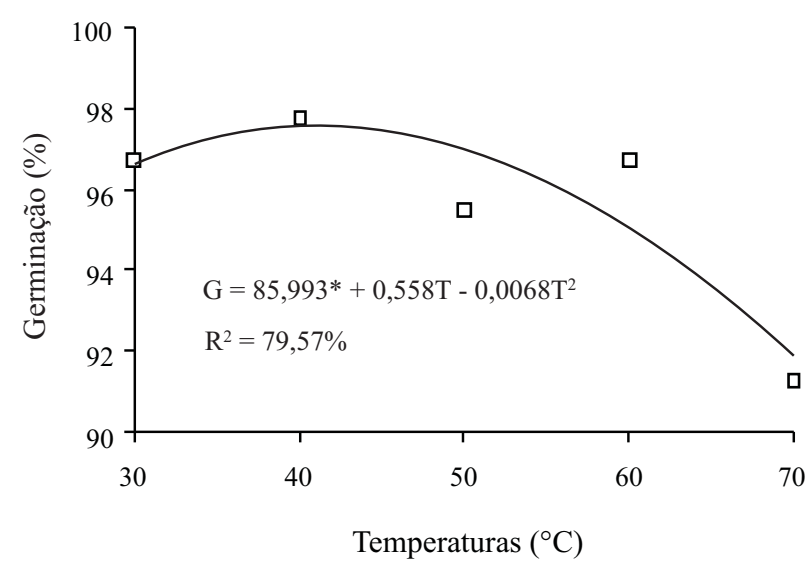

*Significativo a $5 \%$ pelo teste $\mathrm{t}$

Figura 3 - Porcentagem de Germinação $(G)$ em sementes de pinhão manso sob diferentes temperaturas. Instituto Federal Goiano - IFGoiano - Campos Rio Verde - 2009

\section{Conclusão}

Nas condições em que foi desenvolvido o presente trabalho, conclui-se que a temperatura de secagem das sementes de pinhão manso afeta a qualidade fisiológica das mesmas. Com o aumento da temperatura de secagem ocorre maior danificação mecânica das sementes de pinhão manso, porém a germinação ainda se mantém elevada apresentando valores acima de $91 \%$ em todas as temperaturas.

\section{Agradecimentos}

Ao Conselho Nacional de Desenvolvimento Científico e Tecnológico ( $\mathrm{CNPq})$, pelo apoio financeiro indispensável à execução do presente trabalho.

\section{Referências}

ALMEIDA, D. P. et al. Cinética de secagem do feijão adzuki (Vigna angularis). Global Science And Technology, v. 02, n. 01, p. 72-83, 2009.
ARAÚJO, E. F. et al. Qualidade fisiológica de sementes de milho-doce submetidas à debulha, com diferentes graus de umidade. Revista Brasileira de Milho e Sorgo, v. 01, n. 02, p. 101-110, 2002.

BARROZO, M. A. S. et al. The use of the orthogonal collocation method on the study of the drying kinetics of soybean seeds. Journal of Stored Products Research, v. 42, n. 03, p. 348-356, 2006.

BEWLEY, J. D.; BLACK, M. Seeds: physiology of development and germination. $2^{\text {nd }}$. ed. New York: Plenum Press, 1994. 445 p.

BRASIL, Ministério da Agricultura e Reforma Agrária. Secretaria Nacional de defesa Agropecuária. Regras para análise de sementes. Brasília, 2009. 365 p.

BILBAO-SÁINZ, C.; ANDRÉS, A.; FITO, P. Hydration kinetics of dried apple as affected by drying conditions. Journal of Food Engineering, v. 68, n. 03, p. 369-376, 2005.

CARVAlHO, N. M.; NAKAGAWA, J. Sementes: ciência, tecnologia e produção. 4. ed. Jaboticabal: Funep, 2000. 88 p.

CORRÊA, P. C. et al. O. Sorption isotherms and isosteric heat of peanut pods, kernels and hulls. Food Science Technology International, v. 13, n. 03, p. 230-237, 2007.

CORRÊA, P. C.; MARTINS, A. J. H.; CHRIST, D. Thin layer drying rate and loss of viability modelling for rapeseed (canola). Journal of Agricultural Engineering Research, v. 74, n. 01, p. 33-39, 1999.

FUJII, K. Simulação de secagem de sementes de canola (brassica napus) com previsão de germinação. 2007. 131 f. Tese (Doutorado em Engenharia Agrícola) - Universidade Estadual de Campinas, Campinas.

GOLDFARB, M. et al. Teor de água limite para crioconservação das sementes de pinhão manso (Jatropha curcas L.). Revista Brasileira de Produtos Agroindustriais, v. 10, n. 02, p. 121-129, 2008.

GONELI, A. L. D. Variação das propriedades físicasmecânicas e da qualidade da mamona (Ricinus communis L.) durante a secagem e o armazenamento. 2008. $186 \mathrm{f}$. Tese (Doutorado em Engenharia Agrícola) - Universidade Federal de Viçosa, Viçosa.

MAGUIRE, J. D. Speed of germination-aid in selection and evaluation for seedlig emergence and vigor. Crop Science, v. 02, n. 01, p. 176-177, 1962.

MARCOS FILHO, J. Fisiologia de sementes de Plantas cultivadas. Piracicaba: FEALQ, 2005. 495 p.

MIRANDA, L. C.; SILVA, W. R.; CAVARIANI, C. Secagem de sementes de soja em silo com distribuição radial do fluxo de ar. Pesquisa Agropecuária Brasileira, v. 34, n. 11, p. 2097-2108, 1999.

OZDEMIR, M.; DEVRES, Y. O. The thin layer drying characteristics of hazelnuts during roasting. Journal of Food Engineering, v. 42, n. 04, p. 225-233, 1999. 
PRADHAN, R. C. et al. Moisture-dependent physical properties of jatropha fruit. Industrial Crops and Products, v. 29, n. 02/03, p. 341-347, 2009.

SACILIK, K.; TARIMCI, C.; COLAK A. Moisture content and bulk density dependence of dielectric properties of safflower seed in the radio frequency range. Journal of Food Engineering, v. 78, n. 04, p. 1111-1116, 2007.

RESIO, A. N. C.; AGUERRE, R. J.; SUAREZ, C. Analysis of simultaneous water absorption and water-starch reaction during soaking of amaranth grain. Journal of Food Engineering, v. 68, n. 02, p. 265-270, 2005.

SILVA, P. A. et al. Análise fisiológica e ultra estrutural durante o desenvolvimento e a Secagem de sementes de soja. Revista Brasileira de Sementes, v. 29, n. 02, p. 15-22, 2007.
SIRISOMBOON, P.; KITCHAIYA, P. Physical properties of Jatropha curcas L. kernels after heat treatments. Biosystems Engineering, v. 102, n. 02, p. 244-250, 2009.

TEIXEIRA, L. C. Potencialidades de oleaginosas para produção de biodiesel. Informe Agropecuário, v. 26, n. 229, p. 18-27, 2005.

VIEIRA, R. D; PENARIO, A. L; PERECIN, D; PANOBIANCO, M. Condutividade elétrica e teor de água inicial das sementes de soja. Pesquisa Agropecuária Brasileira, v. 37, n. 09, p. 1333-1338, 2002.

VIEIRA, R. D.; KRZYZANOWSKI, F. C. Teste de condutividade elétrica. In: KRZYZANOWSKI, F. C.; VIEIRA, R. D.; FRANÇA NETO, J. B. (Ed.). Vigor de sementes: conceitos e testes. Londrina, PR: ABRATES, p.1-26, 1999. 